Anuario da Facultade de Dereito da Universidade da Coruña

Vol. 20 (2016), pp. 494-496

ISSNe: 2530-6324 || ISSN: 1138-039X

DOI: https://doi.org/10.17979/afdudc.2016.20.0.1956

\title{
M.C. PALOMEQUE LÓPEZ, Vuestros y de la causa obrera. La gran huelga textil de los siete meses en Béjar (1919- 1914), Centro de Estudios Bejaranos (Salamanca, 2016), 325 pgs.
}

\author{
JESÚS MARTÍNEZ GIRÓN \\ Catedrático de Derecho del Trabajo \\ Facultad de Derecho-Universidad de A Coruña
}

Aunque el jurista positivista (y el laboralista lo es) no necesite ordinariamente utilizar lentes correctoras de ningún tipo para poder localizar, poder contemplar a su gusto y poder analizar y, en su caso, criticar las fuentes de conocimiento que pasará luego por el tamiz de la justicia, lo cierto es que no siempre se encuentra ese prototípico laboralista nuestro ante realidades, fenómenos o instituciones de carácter macroscópico, que resulten susceptibles de ser contemplados a simple vista. Cuando esto último ocurre, necesariamente se impone la utilización de algún tipo de lente de ayuda (los comparatistas, por ejemplo, nos vemos frecuentemente compelidos a echar mano de metafóricos telescopios), que en el caso de este magnífico libro del Profesor PALOMEQUE LÓPEZ no queda más remedio que identificar con las lentes de un potente microscopio (yo diría, incluso, que electrónico), únicas que le han permitido llegar a concluir (con frutos doctrinales merecedores de ser jaleados) este libro aparentemente centrado sólo — pero aquí la apariencia engaña - en la anécdota de una huelga funcional y geográficamente muy delimitada, ocurrida hace ahora más de cien años. Con este trabajo, que le exigió al Maestro salmanticense realizar durante dos años un muy duro trabajo de investigación de campo, como el que acostumbran a tener que realizar los grandes historiadores del Derecho (visitando archivos, bibliotecas, hemerotecas y muy diversos registros de documentos públicos), la aparente anécdota de un epifenómeno colectivo local, que se encontraba geográfica, funcional $\mathrm{y}$ temporalmente muy alejado de la macroscopía [lo pone de relieve el subtítulo del libro, sobre La gran huelga de los siete meses en Béjar (1913-1914)], queda elevada al plano superior de muy diversas categorías de máximo interés doctrinal general y actual, tanto formales como de fondo, sobre los que he decidido detenerme por escrito el tiempo que se merecen, tras haber podido leer el libro, realmente tan grato de leer, sin prisas y de un tirón. 
Hablando de categorías formales ilustradas por el libro, lo que se desprende de la fenomenal recopilación y ulterior análisis de fuentes de conocimiento coetáneas realizados por el Profesor PALOMEQUE es el empleo por dichas fuentes de una terminología peculiar, que bautiza a su modo la generalidad de instituciones más primordiales del Derecho colectivo del Trabajo, mediante la utilización de sustantivos o adjetivos que podrían hoy resultar chocantes, sí, pero que tienen toda la veracidad de lo auténtico y toda la vitalidad de lo más intensamente fresco. Así, por poner de relieve sólo unos pocos ejemplos, en dicha documentación (reflejo de una realidad entonces vivida), se califica al sindicato que declaró la huelga como «sociedad de resistencia» (sólo por excepción, hablan estas fuentes de «trabajadores sindicados»). Además, al convenio colectivo denunciado - cuya falta de renegociación actuó como primer detonante de la huelga - se le denomina «contrato de trabajo», sin adjetivarlo de colectivo, identificando al tiempo sus cláusulas como «bases», y como «desahucio» la propia denuncia del mismo. A la huelga se la llama por su nombre, aunque también se la califique expresamente en diversos documentos como «general», y se discuta en otros su carácter «reglamentario» o no (lo que tenía que ver con los estatutos, entonces vigentes, de la UGT) o, incluso, de «política». Y por supuesto, a las cuantías de los salarios - cuya mejora fue objetivo primordial y originario de esta huelga bejarana - se las denomina partout «tarifas». Es cierto que esta última denominación (felizmente recordada por los documentos aplicativos del Derecho, rescatados y sacados a la luz por el Profesor PALOMEQUE) acabó cayendo en desuso en nuestro país. Pero también lo es que sigue poseyendo plena vigencia y rabiosa actualidad en otros de nuestro entorno más próximo, como ocurre en Alemania, en donde su linajuda Ley reguladora de la negociación colectiva sigue denominando todavía al convenio colectivo - sin utilizar ni el sustantivo «convenio» ni el calificativo «colectivo»-, precisamente con su denominación de siempre, esto es, la de «contrato de tarifa [Tarifvertrag]».

Desde el punto de vista de las categorías de fondo, es claro que sigue conservando toda su frescura el debate - tan primorosa y neutralmente expuesto por el Profesor PALOMEQUE - sobre el segundo (y sobrevenido, y a la postre crucial) objetivo de esta huelga, centrado en la pretensión patronal, dinamitadora de la fortaleza del sindicato frente al que luchaba, de que «el trabajo se efectuará indistintamente por obreros asociados ó que no lo estén». En realidad, si utilizásemos categorías modernas, habría que hablar de un debate franco en aquella época sobre pactos de seguridad sindical (y además, pactos duros), en donde las posiciones de los unos y de los otros, expresadas siempre con el lenguaje propio de la época, aparecían meridianamente claras. Para los patronos, por ejemplo, «la facultad natural de asociarse para todos los fines legítimos de ella, es un derecho individual consagrado en la Constitución, y, precisamente por la asignación de tal carácter, no tiene el de obligatorio, como lo entendéis, sino el de potestativo, como nosotros lo entendemos». Frente a esta posición legalista-formalista, los sostenedores de la sociedad de resistencia —que postulaban un «deber de asociación», así como la necesidad de evitar «esta guerra de los organizados contra los inorganizados»- afirmaban, por su parte, con crudo realismo material, todo lo siguiente: «Naturalmente, á los patronos no les conviene esto, porque de ese modo, al disminuir ó desaparecer los obreros que venden á precios degradantes su trabajo, los jornales han de ser, por término medio, más altos y los dividendos algo más bajos; 
aunque está probado que á mayores jornales y menores jornadas corresponde una productividad mayor, que compensa con exceso á los patronos». Quizá no haga falta aquí insistir en que este debate de hace más de cien años seguirían considerándolo vital $\mathrm{y}$ actual nuestros colegas laboralistas anglosajones (y especialmente, los norteamericanos) e, incluso, la propia OIT, haciendo patente la conexión (o si se quiere, el puente de piedra) entre aquella época y la nuestra, tan distantes en el tiempo, especialmente la primorosa nota al pie número 474 de este fenomenal estudio de historia del Derecho colectivo del Trabajo español, que a todos nos invita a disfrutar. 